\title{
LAS LÍDERES MUNDIALES Y SUS ESTRATEGIAS ANTE EL COVID-19
}

\section{FEMALE WORLD LEADERS AND THEIR STRATEGIES AGAINST COVID-19}

Dra. Tamara Morales Owseykoff ${ }^{\text {a }}$

Dra. Eira López Fernández ${ }^{\text {b }}$

Dr. Jorge Antonio García Gálvez ${ }^{\mathrm{c}}$

\begin{abstract}
${ }^{a}$ Universidad Veracruzana Instituto de Investigaciones en Contaduría, tamorales@uv.mx

${ }^{\mathrm{b}}$ Universidad Veracruzana Instituto de Investigaciones en Contaduría, eilopez@uv.mx

${ }^{\mathrm{c}}$ Universidad Veracruzana Instituto de Investigaciones en Contaduría, jorgarcia@uv.mx
\end{abstract}

\section{RESUMEN}

Este artículo tiene como objetivo compilar y resaltar las estrategias aplicadas por distintos gobiernos encabezados por mujeres contra el COVID-19, así como los resultados obtenidos en siete países, al inicio de la misma: Alemania, Dinamarca, Finlandia, Islandia, Noruega, Nueva Zelanda y Taiwán. En los siete países mencionados, a excepción de Alemania que tardó en controlar el número de contagios y muertes, la pandemia fue controlada. El común denominador de estos países ante la pandemia, además de tener una líder de gobierno mujer, es el buen resultado obtenido con el confinamiento o cuarentena, en su mayoría no obligatorio, desde el inicio de esta; dicha acción fue clave para controlarla a tiempo y que sus cifras de población afectada fueran bajas. La información se obtuvo de distintas fuentes periodísticas, blogs, páginas web, agencias de información y la Organización Mundial de la Salud (OMS), por lo novedoso del fenómeno y la lenta documentación de la pandemia.

PALABRAS CLAVE: COVID-19; estrategias; Mujeres; Gobierno. 


\section{ABSTRACT}

This article aims to compile the strategies applied by different governments headed by women against COVID-19, as well as the results obtained, in seven countries: New Zealand, Iceland, Germany, Denmark, Finland, Norway and Taiwan. In all these countries, except for Germany, which was slow to control the number of infections and deaths, the pandemic has been controlled. The common denominator of these countries in the face of the pandemic, in addition to having a female government leader, presents clear results, the confinement or quarantine in these countries, mostly not mandatory, since the beginning of the pandemic, was the key to control it in time and that their numbers of affected population were low. The information was obtained from different journalistic sources, blogs, web pages, information agencies and the World Health Organization (WHO), due to the novelty of the phenomenon and the slow documentation of the pandemic.

KEYWORDS: COVID-19; Strategies; Women; Government.

\section{INTRODUCCIÓN}

El coronavirus está modificando actualmente en forma dramática la vida ... Nuestra idea de la normalidad, de la vida pública, de la convivencia social, está siendo puesta a prueba como nunca antes ... Somos una comunidad en la que cada vida y cada persona cuentan (DW, 2020).

Merker (2020)

La actual pandemia COVID-19, causada por el virus SARS-CoV-2, ha sido una clara muestra de cómo cada ser humano responde distinto ante una situación de peligro; las generaciones actuales no se habían enfrentado a una situación así, o por lo menos no tan alarmante como esta; la última pandemia registrada después de 40 años fue en 2009 con el virus de la influenza A(H1N1) dejando más de 300 mil personas muertas de acuerdo con el centro para el Control y Prevención de Enfermedades (CDC). Los protocolos existentes para dicho virus se limitaron a la aplicación de la vacuna anualmente; no se esperaba la 
propagación de otro virus por lo que no existía un protocolo sanitario, ni rutas de acción de cómo comportarse como ciudadanos.

Cada país lo asumió desde su muy particular perspectiva y contexto social, económico, educativo, etc., pese a contar con algunos lineamientos por parte de la Organización Mundial de la Salud (OMS). Desde estas perspectivas, podría asumirse que los países más desarrollados tendrían una mejor respuesta ante la situación al contar con un nivel educativo por encima de otros países del mundo, a su organización social, a su capacidad para comprar insumos e invertir en campañas de difusión, de adquisición de material de protección y provisión de servicios de salud a la altura de las circunstancias, etc., sin embargo, tenemos claras muestras de lo contrario con casos como Estados Unidos, España, Francia, Reino Unido o Francia, por citar solo algunos, donde se han registrado un gran número de contagios y decesos causados por el virus, en gran medida al fracaso de una cadena de decisiones inadecuadas y una carente estrategia de prevención.

Cada uno de los presidentes o primeros ministros de distintos países han presentado ciertos rasgos característicos en el manejo de la pandemia. Hombres y mujeres han definido distintas formas de actuar. Este estudio se centrará en las estrategias que las mujeres, ejerciendo el poder, han implementado en forma exitosa, por lo que se eligió un grupo de siete países que, desde el inicio de la pandemia y hasta la fecha, son los que mejor están gestionando la crisis del coronavirus conteniendo los contagios y fallecimientos. Se presentará un breve currículo de las líderes seleccionadas, rasgos que identifican su gestión, estrategia elegida, situación del país desde el punto de vista de salud, medidas económicas y comunicación y cooperación política. En esta lista se encuentran:

- Alemania, Angela Merkel

- Dinamarca, Mette Frederiksen

- Finlandia, Sanna Marin

- Islandia, Katrín Jakobsdóttir

- Noruega, Erna Sulberg

- Nueva Zelanda, Jacinda Ardern 
- Taiwán, Tsai Ing-wen

\section{II. ¿QUIÉNES SON ESTAS LIDERES? BIOGRAFÍA, ESTILOS DE GESTIÓN, ESTRATEGIAS Y MEDIDAS ECONÓMICAS.}

\section{1 Angela Merkel 1954, Hamburgo Alemania.}

\section{II.1.2 Biografía.}

Se le considera la mujer más destacada en la Política alemana, como presidenta del partido alemán Unión Demócrata Cristiana desde 2000 y canciller de la República Federal de Alemania desde 2005. Fue la primera mujer que asumió la jefatura del Gobierno federal desde que nació el Estado Alemán (1870), y también el primer canciller originario de la extinta República Democrática Alemana (RDA).

Angela estudió Física en la Universidad de Leipzig, doctorándose con una tesis sobre química cuántica, en 1986. Estuvo trabajando como investigadora en la Academia de las Ciencias de la República Democrática Alemana (RDA). Tras la caída del Muro comienza una rápida carrera política, desempeñando cargos de ministra de Juventud y Medio Ambiente. Colabora con el canciller Helmut Kohl y le sucede como secretaria general y presidenta del partido. En los años sucesivos, aunque con dificultades por críticas y reticencias dentro de su partido, adquiere una gran popularidad.

Tras varias tensiones y negociaciones entre diferentes facciones del partido conservador se consiguen acuerdos para hacer una coalición. A finales de 2005 el Bundestag (Parlamento Federal) elige a Angela Merkel como Canciller de Alemania. El 27 de noviembre de 2009 gana las elecciones, siendo la candidata más votada. A partir de la presidencia alemana en la Unión Europea, Angela Merkel, ha conseguido posicionarse como una de las líderes más importantes de Europa, y del mundo cabe decir, siendo el centro de todas las decisiones, el resto de los países le rinden cuentas. (Biografía de Angela Merker, 2019). 
Merker es conocida por la firmeza en sus decisiones y la claridad para abordar los problemas de su país, es reconocida por guiar a sus conciudadanos con mensajes directos, contundentes y simples. Se presentó en televisión nacional comunicando que se enfrentaban a una situación sin precedentes, peligrosa y en la que todos debían contribuir a paliar el problema. Se asesoró por la comunidad científica y siguió todas recomendaciones que le fueron propuestas. Alemania presentó desde marzo del año 2020 la tasa de mortalidad por COVID-19 más bajas entre los países europeos y con el mismo nivel socioeconómico, el Instituto Robert Koch (RKI) tenía contabilizados 67.366 casos confirmados y 732 muertes. Esto supone una tasa de letalidad del 0,8\%, mientras que en Italia esa tasa es de más del 11\%, y en España supera el 8\%. (López, 2020) La tasa de infección ha disminuido a menos de 1 por cada persona que lo ha hecho, lo que arroja una disminución en la tasa de contagio que hoy les permite relajar algunas de las medidas de distanciamiento social. A todas luces, Alemania se muestra como uno de los países que mejor parece estar manejando la crisis. Las medidas de relajamiento social no han aumentado los casos y los ciudadanos muestran disciplina en aplicar las indicaciones de las autoridades de salud. Ahí la vida sigue sin merma de las actividades cotidianas, los niños van al colegio, las oficinas públicas siguen trabajando en horarios normales y la población que se denomina de "riesgo" adultos de la tercera edad no han cambiado sus rutinas drásticamente.

\section{II.1.2 ¿Cuál es la estrategia alemana?}

Como explicaciones de estos resultados favorables, los analistas mencionan algunos factores externos a la gestión propiamente dicha del gobierno. Un sistema de salud funcionando ejemplarmente: con los equipos de seguridad sanitaria (EPIs -equipos de protección individual-, tapabocas, guantes, respiradores y suministros varios), espacios disponibles en la hospitalización y cuidados intensivos por habitante. Sumado a ello, el país venía fortaleciendo su sistema hospitalario desde hace muchos años (algo que irónicamente fue criticado en el pasado) y tiene una cobertura universal de salud lo que elimina cualquier barrera de acceso a las pruebas por razones económicas. Alemania dispone de 25.000 camas con los respiradores y 29.2 camas de cuidados intensivos por cada 100.000 habitantes (ABC internacional, 2020). Otro factor es la capacidad de administración de 
pruebas COVID-19 y el rastreo de casos resultan los factores más mencionados. Mientras en el Reino Unido, por ejemplo, se hacían a mediados de abril sólo 5,7 pruebas por cada 1,000 habitantes, en Alemania la cifra ya era de 24,7 en abril 19 2020. La realización masiva pero también focalizada de pruebas, no sólo les permitió aislar las personas infectadas para luego rastrear sus contactos, sino también posibilitó tratar tempranamente a las personas con síntomas severos. Esta identificación temprana de los pacientes parece hacer una gran diferencia para poder reducir la fatalidad de los casos. Merkel desde el poder afianzó el sistema sanitario sin pensar en la pandemia, sino en el bienestar de los ciudadanos con una buena visión de futuro.

\section{II.1.3 Medidas económicas}

En medio de la batalla, las medidas de salud vinieron acompañadas de ayudas económicas rápidas y efectivas, que permitieron a los alemanes abrazar las medidas estrictas de aislamiento social, sin miedo a quedar sin recursos. Por ejemplo, se expandió el acceso al subsidio de trabajo y se destinaron 50 mil millones de euros en subsidios a propietarios de pequeñas empresas y trabajadores independientes afectados por la pandemia. En tanto, un mayor gasto en salud para ampliar la capacidad de respuesta del sistema ha sido posible gracias a un presupuesto suplementario de $€ 156$ miles de millones de euros (4.9\% del PIB). Ella y su gobierno tuvo la perspectiva de atender la emergencia y además apoyar económicamente a las empresas más vulnerables y que son claves para seguir con la actividad económica.

\section{II.1.4 Comunicación y cooperación política}

Existen dos acciones más, la primera, en Alemania la comunicación ha sido transparente, abierta, y liderada por científicos, en especial virólogos y epidemiólogos, para comunicar la evolución de la situación y las medidas tomadas. Las distintas medidas que adoptan los gobiernos para mitigar el brote y sus efectos sobre la economía deben ser comunicadas de manera clara, con sensibilidad, pero con la contundencia suficiente que le permita a la ciudadanía confiar en las estrategias que están siendo adoptadas en procura de salvar vidas y salvaguardar el bienestar social. (Gideion \& Góngora, 2020) Merkel se supo asesorar de 
personas conocedoras de los riesgos y hacer caso de sus reportes científicos para no difundir información que dañara, aún más, la salud de sus conciudadanos.

\section{2 Mette Frederiksen 1977, Aalborg Dinamarca.}

\section{II.2.1 Biografía}

La política del Partido Socialdemócrata danés y primera ministra de Dinamarca desde el 27 de junio de 2019. Ha sido miembro del Folketing, el parlamento de Dinamarca, desde 2001.

Formó parte del gobierno de Helle Thorning-Schmidt como ministra de Trabajo desde 2011 al 2014 y como ministra de Justicia entre 2014 y 2015. El 28 de junio de 2015 sucedió a Thorning-Schmidt como dirigente del Partido Socialdemócrata. Estudió en el Instituto Aalborghus Gymnasium; posteriormente cursó Administración y Ciencias Sociales en la Universidad de Aalborg. Después de graduarse en el año 2000, trabajó como asesora de juventud para LO (Landsorganisationen i Danmark, en danés), la Confederación Danesa de Sindicatos. Fue elegida parlamentaria por el distrito de Copenhague en las elecciones generales que tuvieron lugar el 20 de noviembre de 2001. Después de ser electa fue nombrada portavoz de su partido para cultura, medios de comunicación e igualdad de género. Se convertiría en la portavoz de su partido para asuntos sociales tras las elecciones parlamentarias de 2005. También tras las elecciones de 2005, pasó a ocupar el cargo de vicepresidenta del grupo parlamentario del Partido Socialdemócrata. (CIDOB, 2019a)

Su temple y postura firme sobre sus acciones la han caracterizado en su desempeño como primera ministra. El compromiso con su trabajo es primordial. Conocida por contestar con claridad a Donald Trump por comentarios banales y fueras de contexto o por cancelar su boda en tres ocasiones por atender la estrategia de la pandemia o compromisos europeos. Eso perfila un carácter definido y anteponiendo todas sus actividades públicas y privadas para dirigir todas sus fuerzas en prevenir, gestionar y dar resultados convenientes para los daneses. 


\section{II.2.2 ¿Cuál es la estrategia danesa?}

Dinamarca realizó el cierre anticipado de las fronteras (específicamente el 13 de marzo) siendo uno de los países que adopto en forma temprana una estrategia de confinamiento que favoreció a la población para mantenerse a salvo de la pandemia de COVID-19.

Favorecida por su situación geográfica, la península danesa sólo tiene colindancia con dos países en forma terrestre Alemania y Suecia, ambos países con una de las tasas bajas de contagios por Covid-19, en comparación con sus vecinos europeos. Eso ha favorecido su buen manejo y la no propagación del virus.

La disciplina es una de las características conocidas del pueblo danés, lo cual favoreció que se acataran las medidas de distanciamiento social, higiene constante y uso de medios preventivos como: cubrebocas, guantes o caretas faciales. Estas medidas no fueron obligatorias, sin embargo, si fueron usadas por la población con la finalidad de mantener la salud.

\section{II.2.3 Medidas económicas}

Cuando estamos frente a desafíos como los de esta pandemia mundial, las mentes que dirigen los países se vuelven los y las protagonistas de su desenvolvimiento. Y sus acertadas decisiones económicas, serán clave.

El teletrabajo, más desarrollado y aceptado en Dinamarca, permitió un despliegue más veloz e intuitivo del recurso al trabajo en casa desde las primeras señales de la crisis sanitaria. Las personas siguieron recibiendo su salario no importando donde lo realizaban, por lo que su situación económica no se vio mermada, todo lo contrario, el gasto común siguió en niveles casi normales. Comercios como restaurantes, bares, peluquerías y grandes centros comerciales cerraron no llegaron al cierre definitivo, ya que el gobierno aprobó un paquete de apoyos financieros que les ha permitido sobrevivir. Un punto más a favor de la economía fue mantener los pequeños comercio y supermercados abiertos así muchas fuentes de trabajo pudieron conservarse. La confianza en el proceder de los daneses fue clave para el 
gobierno, los comercios acataron las indicaciones de no saturación o mantener el máximo de aforo de 10 personas dentro de los establecimientos, limitaron las reuniones familiares o entre amigos, práctica de ejercicios al aire libre con suficiente distancia social., entre otras. El civismo jugo un papel muy importante para la contención de la pandemia. Dinamarca ha sido de los primeros en anunciar planes concretos para una reapertura controlada y prudente tras la cuarentena. Con el objetivo de evitar un impacto económico mayor, el Gobierno danés optó por un acuerdo temporal con empresarios y sindicatos, cubriendo el $75 \%$ del sueldo de los trabajadores de empresas privadas que podrían perder sus empleos por la crisis del coronavirus. A mediados de abril se han marcado pautas para regresar a una cierta normalidad escolar, los niños menores de once años regresaron a clases. Acatar adecuadamente las pautas recomendadas por el gobierno, la anticipación de cierre de fronteras y un plan de apoyo financiero permitieron que la economía se mantuviera fuerte y los puestos de trabajos se resguardaron adecuadamente para beneficio de la población. (Makooi, 2020)

\section{II.2.4 Comunicación y cooperación política}

El gobierno aún no ha permitido el desconfinamiento total, sin embargo, los jóvenes retomaron clases bajo lineamientos estrictos, los niños deben permanecer la mayor parte de su jornada escolar en el exterior de sus aulas, compartiendo con los mismos compañeros de su burbuja o grupo (tres a cinco compañeros) y así guardar el control de los contactos físicos de cada uno de ellos. Realizar actividades en grupos identificados permitió la detección rápida de casos de COVID-19 entre niños y maestros.

En cuanto a los estudiantes de secundaria y bachillerato, esperaron hasta el 10 de mayo antes de regresar a las aulas, así como la apertura de restaurantes y bares.

De igual manera, todavía están prohibidas las grandes aglomeraciones de personas o los eventos deportivos y culturales, lo cual solo sería posible autorizar hasta, como muy pronto. Este desconfinamiento escalonado será una prueba. El Gobierno danés promete observar muy de cerca las cifras de contaminaciones con el fin de ajustar 
las etapas de las reaperturas o de endurecer las medidas en caso de ser necesario. (Makooi, 2020)

\section{3 Sanna Mirella Marin 1985, Helsinki Finlandia.}

\section{II.3.1 Biografía}

Sanna nació en un hogar homoparental, es decir, de una familia formada por dos personas del mismo sexo. En el 2007 emprendió estudios superiores en la Universidad de Tampere (UTA).

En 2006 se unió a la Juventud del Partido Socialdemócrata de Finlandia (SDP). En 2010, Marin fue elegida vicepresidenta de la Juventud Socialdemócrata y de paso miembro del Consejo Ejecutivo del SDP (CIDOB, 2019b).

Se licenció en Ciencias Administrativas por la Universidad de Tampere (UTA) en 2012 con especialidad en gestión y gobiernos locales y cuenta con una Maestría en Ciencias Administrativas. Se desempeño como edil en la ciudad de Tampere de 20121 2017.En las municipales de octubre de 2012 Marin, recién licenciada en Ciencias Administrativas por la UTA, ganó por méritos propios el puesto de edil de Tampere, cuyo Consejo Municipal presidió asimismo entre 2013 y 2017. Además, se desempeñó en el Consejo Regional de Pirkanmaa. (CIDOB, 2019b)

En 2017 fue elegida vicepresidente primera del Partido Social Demócrata (SDP) de Finlandia. El mismo año fue reelegida como munícipe en Tampere, en muy poco tiempo empezó a ser reconocida y su ascenso rápido, llegando a ser primera ministra muy poco tiempo después.

Marin una mujer seria, introvertida y con una gran popularidad ha manejado la pandemia de una forma discreta pero efectiva. El Gobierno de Finlandia decretó el estado de alarma por el coronavirus a mediados de marzo, presentando un paquete de medidas que incluía algunas como el cierre de las fronteras y la clausura de todos los centros educativos del país para frenar la expansión de la epidemia. 


\section{II.3.2 ¿Cuál es la estrategia finlandesa ?}

Anunciando también el cierre de bares, cafés, discotecas y restaurantes hasta el 31 de mayo, y ordenan del aislamiento de la región más poblada, Uusimaa, que incluye la capital, Helsinki, donde la presencia del virus cuenta con una tasa de contagios que dobla al del resto del país. La primera ministra aseguró en abril.

Mediante una respuesta temprana, hemos logrado frenar la progresión de la epidemia y hasta ahora hemos sido capaces de evitar un pico pronunciado de la enfermedad. Esto ha sido posible gracias a todos los que han actuado de forma responsable (Redacción, 2020).

Finlandia ha mejorado su situación con respecto a la pandemia y ha empezado a retirar algunas de las restricciones, como abrir las fronteras parcialmente y la vuelta al colegio de loa estudiantes de todos los grados haciendo uso de una estrategia hibrida -llamada así por impartir la educación de dos formas presencial y virtual o vía remota- esto con el fin de no permitir que se disemine el virus entre la población.

Según Marin (Redacción,2020) es necesario continuar con la estrategia híbrida para prevenir la propagación del coronavirus hasta que la epidemia esté bajo control a nivel global, de forma tajante.

Finlandia ha aumentado ya el número de test y la capacidad de seguimiento de las cadenas de contagio, y está preparando cambios legislativos para regular el uso de aplicaciones móviles que faciliten el rastreo de nuevos casos (Redacción, 2020).

Según Taneli Puumalainen, uno de los responsables del Instituto Nacional de Salud y Bienestar (THL), Finlandia superó el pico de la pandemia a mediados de abril y desde entonces el ritmo de contagios se ha frenado de forma leve pero constante (Redacción, 2020).

\section{II.3.3 Medidas económicas}

Morales T., López E. \& García J. A.

Las líderes mundiales y sus estrategias ante el COVID-19 
Si bien no se detallan las medidas económicas con precisión, se deduce que el modelo hibrido para limitar la propagación de la pandemia es proporcionar apoyos financieros a todos los trabajadores para no ocasionar un desbalance de las finanzas del país.

\section{II.3.4 La Comunicación y cooperación política}

Cada vez, que el Ejecutivo recurre a una estrategia de comunicación para publicar las recomendaciones de las autoridades sanitarias, considera los medios de comunicación.

El entorno de Internet ha creado nuevos canales para difundir mensajes e influir en la sociedad. Herramientas, como las redes sociales, ahora conviven con los medios de comunicación en el nuevo panorama. Y Finlandia lo ha entendido. El Gobierno mandó mensajes para minimizar los casos de contagio a través de personajes conocidos en las redes sociales con el objetivo de llegar de este modo a los jóvenes del país. (Redacción,2020)

\section{4 Katrín Jakobsdóttir 1976, Islandia Reykjavík.}

\section{II.4.1 Biografía}

Jakobsdóttir se diplomó en 1999 en Filología Islandesa y Francesa por la Universidad de Islandia. Ella es parte de una familia prominente en el mundo intelectual, artístico y político. En el 2007 inició su carrera parlamentaria por la circunscripción norte de Reikiavik. En el 2009 participo en un gobierno provisional, integrado por su partido, llegando a ser la ministra de Educación.

El 30 de noviembre de 2017 asumió como primera ministra de Islandia, luego de acordada una coalición entre el Movimiento de Izquierda-Verde, el Partido de la Independencia y el Partido Progresista (CIDOB, 2017b).

Jakobsdóttir la primera ministra que tiene una excelente popularidad, considerada una mujer muy trabajadora, simple, muy centrada en los diversos temas que atañen a Islandia. 
Eso le permite trabajar de forma muy cercana con expertos, estrategas y plantear una buena logística para minimizar el impacto de la pandemia.

\section{II.4.2 ¿Cuál es la estrategia islandesa?}

Islandia ha logrado que sus niveles de contagio disminuyan sin tener que imponer medidas drásticas en toda la isla. Su primer caso fue detectado el 28 de febrero y eso puso en marcha todo un mecanismo de protección y de cuidados hacia la población. Se consideró que realizar pruebas masivas a la población era la mejor opción para minimizar los contagios y tener controlada la propagación del virus. Aquí se hizo uso de rastreadores de alta tecnología que identificaban quiénes y en qué lugar habían permanecido identificando si habían tenido contacto con alguna persona contagiada.

El rastreador islandés, Rakning C-19, se lanzó a principios de abril y desde su lanzamiento fue aclamado como un modo de "facilitar el rastreo de contagios". Realiza un seguimiento de los datos de GPS de los usuarios para crear un registro de su ubicación, permitiendo a los investigadores, con autorización previa, comprobar si los diagnosticados con COVID-19 podían haber estado propagando la enfermedad. (Johnson, 2020)

Aquí se hizo un uso muy positivo de la tecnología para la identificación de los casos de contagio, pero se considera que el seguimiento por medio de llamadas telefónicas o manual fue aún más efectivo.

Islandia ha podido controlar los contagios del virus COVID-19. Se tiene registrado que a mediados de mayo se tenían 1,800 casos confirmados con tan solo 10 defunciones.

La vida en la isla ha cambiado mucho se considera que es un país que ha implementado unas de las medidas más drásticas observadas en otros lugares. Además, se implementó el 
distanciamiento social generalizado y en la educación se hizo uso de los grupos o burbujas para que los niños se mantuvieran siempre en contacto con los mismos compañeros y así evitar el número de contagios o si los hubiese se rastrearía con facilidad en dónde se generó el brote.

Lo que ha funcionado bien ha sido la acción temprana y agresiva centrada en realizar las pruebas de diagnóstico, rastrear y aislar, así como trabajar en un modelo de colaboración con los ciudadanos (Johnson, 2020).

\section{II.4.3 Medidas económicas, comunicación y cooperación}

Las medidas económicas no se resaltan ni son difundidas por las autoridades. La comunicación se dio a través de las redes sociales y de las aplicaciones que detectaban los casos positivos. La cooperación de la ciudadanía ha sido ejemplar entendiendo la gravedad del problema.

\section{II.5 Erna Solberg 1961, Bergen Noruega.}

\section{II.5.1 Biografía}

Procede de un hogar de clase trabajadora. Graduada de la Universidad de Bergen en 1986 en Ciencias Políticas, Sociología, Economía Social y Estadística. Se Le considera conservadora iniciando su carrera política en 1979 en el ayuntamiento donde estudio. El Partido Conservador Noruego (Høyre) -palabra que en noruego significa derecha- es en el que ella ha participado desde sus inicios en política. Se convirtió en la segunda mujer en ser primera ministra después de suceder a Gro Harlem Brundtland en 2013.

Solberg es una mujer fuerte dirigiendo un país económicamente estable y con buenos niveles de popularidad. Ella, similar a sus contrapartes de los países mencionados, se enfrentó a una población con comunicados claros, constantes y dando indicaciones precisas en el inicio de la pandemia pero que al final le dieron un buen resultado (CIDOB, 2013).

\section{II.5.2 ¿Cuál es la estrategia de los noruegos?}


Para frenar la pandemia causada por el coronavirus COVID 19, Noruega mantiene cerradas sus fronteras desde mediados de marzo (Visitnorway,2020).

Solo pueden entrar en el país personas con pasaporte noruego o con permiso de residencia o trabajo. El gobierno decidirá sí en las próximas semanas si permite la entrada de turistas de países europeos no escandinavos este verano. Entre ellas, el cierre de fronteras a los extranjeros sin permiso de residencia o trabajo. La situación, que se revisa regularmente, es ahora la siguiente: el 15 de junio, el gobierno noruego decidió que reabría las fronteras a visitantes procedentes de los países nórdicos. Y antes del 20 de julio prevé anunciar si se permite la entrada en Noruega de turistas de otros países europeos este verano. A la espera de esas posibles decisiones, el cierre de fronteras decretado a mediados de marzo para todos los extranjeros sin permiso de residencia o trabajo en Noruega seguirá en vigor hasta el 20 de agosto.

La cuarentena es una de las medidas que ha implementado para poder cuidar la salud de los noruegos. Los connacionales o con visas de trabajo o permisos de residencia que hayan visitado otros países deberán guardar cuarentena por diez días tras su regreso al país para vigilar su salud y evitar los contagios en su caso.

Según medio oficiales locales noruegos, se dispuso que todas aquellas personas con pasaporte noruego o permiso de residencia o de trabajo en Noruega y que hayan estado recientemente en otros países deberá guardar cuarentena en casa durante 10 días tras su regreso a Noruega, tengan o no síntomas.

Y como en todos los casos del mundo, cuando alguien presenta síntomas del virus debe ser puesto en aislamiento, variando siempre los días del mismo.

En general, todas las personas llegadas desde otros países han de guardar cuarentena si desean permanecer en Noruega. Solo estarán exentos, según la regulación vigente, aquellos cuyo viaje desde casa al puesto de trabajo implique cruzar las fronteras entre Suecia, Finlandia y Noruega. 
En otras palabras, Noruega, se envolvió en una burbuja para protegerse y confiando en sus ciudadanos y su forma de responder ante esta situación adversa.

\section{6 Jacinda Ardern 1980, Hamilton Nueva Zelanda.}

\section{6. 1 Biografía}

Jacinda Arder estudió en la universidad Universidad Waikato en la ciudad donde nació y vivió, en Hamilton. En 2001 se graduó en Communication Studies con un énfasis en relaciones públicas y políticas.

Criada en un hogar de clase trabajadora y religión mormona. Educación superior en la cercana Universidad Waikato de su ciudad natal, Hamilton, por la que en 2001 se graduó con el título de Bachelor of Communication Studies, que ella deseaba orientar a las relaciones públicas y la política. Al terminar la carrera en Waikato, Ardern fue reclutada por la entonces líder del Partido Laborista de Nueva Zelanda y jefa del Gobierno, Helen Clark, como asistenta académica adscrita a la Oficina del Primer Ministro. Joven con inquietudes sociales e internacionales, la futura dirigente neozelandesa pasó sendas temporadas en Nueva York, para realizar labores de voluntariado a pie de calle, en barrios golpeados por la indigencia, y Londres, donde trabajó en el equipo de asesores políticos del primer ministro laborista Tony Blair, así como para el Departamento británico del Interior. (CIDOB, 2017a)

Arder tiene una trayectoria impecable, constante y la hace convertirse en un referente en su país.

Activa, en 2008, fue electa presidenta de la Unión Internacional de Juventudes Socialistas. Después, fue elegida por unanimidad como subdirectora del Partido 
Laborista; años más tarde, en el 2017 llegó como líder del partido y bajo su liderazgo y rumbo objetivo, el Partido Laborista quedó por delante de su rival tradicional, el Partido Nacional, por primera vez en doce años, convirtiéndose así en la actual y primera ministra de Nueva Zelanda. (CIDOB,2017a)

Ideológicamente, se describe a sí misma como una socialdemócrata, progresista, republicana y feminista. Sobre cuestiones culturales, es partidaria del matrimonio entre personas del mismo sexo, habiendo votado a favor del proyecto de ley de igualdad matrimonial en 2013 y apoya la liberalización de las leyes sobre el aborto. (CIDOB, 2017a)

Jacinda Ardern, una mujer menuda y afable que demostró un fuerte carácter desde el atentado a las mezquitas en la capital donde hubo víctimas mortales y por las que coordinó un operativo en el que en menos de 4 horas se tenía un panorama claro sobre lo ocurrido, sacó a la luz sus rasgos para gestionar contingencias. Amy Cuddy, 2009, publicó un artículo donde hace referencia a la percepción que se tiene de las mujeres, ella reflexiona que no por el hecho de verse sencilla y pacífica significa que carece de habilidades. Cuddy, en agosto de 2020, publicó en redes sociales una nota sobre el comportamiento de Ardern y que de forma adecuada ha aplicado un estilo simple pero firme.

\section{6.2 ¿Cuál es la estrategia de los neozelandeses?}

Al presentarse el primer caso en Nueva Zelanda se implementaron los operativos dirigidos por Jacinda Ardern.

El primer caso confirmado de COVID-19 se registró el 28 de febrero. La enfermedad no avanzó mucho en las siguientes dos semanas, con sólo seis contagios registrados hasta el 14 de marzo. Aun así, la primera ministra Ardern ordenó ese día que todo viajero que llegara a su país, nacional o extranjero, se pusiera en cuarentena por 14 días sin excepciones, así como el veto a los cruceros, un movimiento difícil para un país muy vinculado al turismo. (BBC News Mundo, 2020) 
Jacinda dijo que su plan incluía las restricciones fronterizas más amplias y duras de cualquier país del mundo, pero eso era sólo el comienzo. Para el 19 de marzo llegó el cierre total de fronteras. Las medidas tan estrictas tomadas por la ministra fueron sin duda de las más eficaces a la hora que presentó el sistema de alertas de cuatro niveles. Con ello demuestra la efectividad de su plan estratégico ya que, para el 23 de marzo, Nueva Zelanda sólo superó los 100 casos en menos de un mes (sin ninguna muerte todavía) y aplicó el nivel 3 de su respuesta a la pandemia. (BBC News Mundo, 2020)

"Estamos yendo duro y temprano", dijo Ardern a sus ciudadanos. "Sólo tenemos 102 casos, pero también Italia los tuvo una vez". Dio un plazo de 48 horas para la activación del nivel 4, llamado "eliminación", el cual estableció la cuarentena obligatoria para los 4,8 millones de habitantes del país por cuatro semanas. Nadie podía dejar su casa, a menos de que uno de sus habitantes saliera para comprar víveres, medicinas o acudir al médico. Solo estaba permitido hacer ejercicio o tener esparcimiento en los alrededores de casa. (BBC News Mundo, 2020)

También se dio la cancelación total de actividades no esenciales, lo que implicaba el cierre de escuelas, comercios (exceptuando los de víveres y farmacias), industrias y servicios.

A partir de la activación del nivel 4 el 25 de marzo, los nuevos casos confirmados se contaban por decenas en los siguientes diez días, con el número más alto (76) el día 28 y la primera muerte al 29. Pero entonces el efecto de la estrategia de "eliminación" comenzó a ser evidente. Ha sido una de las estrategias más duras en el mundo, pero desde el 22 de mayo no reportan nuevos contagios. (BBC News Mundo, 2020). Sólo 75 días después de declarar el nivel más alto se controlaron los contagios con una estrategia de confinamiento y poca circulación. El 8 de junio Nueva Zelanda declara la superación de la pandemia, lo había logrado, no había ningún infectado por COVID en su territorio. (Proceso, 2020). Gran éxito y reconocimiento por todos los países del mundo. En el mes de agosto se 
reportaron 4 casos de nuevo y fue tajante: confino de nuevo a la población para evitar una desgracia.

\section{7 Tsai Ing-Wen 1956, Taipei Taiwán.}

\section{7. 1 Biografía}

Las raíces pueden muchas veces ser una parte fundamental en nuestro desarrollo, esta mandataria viene de una familia con toda mucha historia.

De linaje multiétnico, Tsai Ing-Wen es la menor de 11 hermanos y hermanastros, la presidente de Taiwán posee formación jurídica recibida en la Universidad Nacional de su país, la Universidad de Cornell y la London School of Economics (LSE), centros en los que recibió respectivamente la diplomatura en 1978, la licenciatura en 1980 y el doctorado en Derecho en 1984. (CIDOB, 2016)

Trabajó en diversas oficinas gubernamentales como la Comisión de Comercio Legal, la Comisión de Derechos de Autor y miembro del Consejo de Seguridad Nacional. En el año 2000, Tsai recibe el cargo de Ministra de Asuntos Continentales en el gobierno de Chen Shui-Bian como independiente. En el 2004 se postuló por su partido para las elecciones legislativas de ese año y fue electa parlamentaria, en donde trabajó como presidente de la Comisión de Protección al Consumidor. (CIDOB, 2016)

En 2006, Tsai fue electa vicepresidente del parlamento de la República de China cargo equivalente al de viceprimera ministra.

Fue la principal candidata de la oposición en las disputadas elecciones presidenciales del 2012.

(primera candidata mujer en la historia de las elecciones presidenciales taiwanesas), donde recibió el 45,6 \% de los votos, frente al 51,6 \% del presidente Ma Ying-jeou, 
quien buscaba la reelección. Tsai reconoció su derrota el mismo día por la noche y deseó suerte al presidente Ma en su segundo gobierno. (CIDOB, 2016)

Contendió nuevamente en las siguientes elecciones y Taiwán la eligió en enero de 2016.

Como su primera presidenta mujer, junto a Chien-Jen Chen, luego de concederle a su partido, el Partido Democrático Progresista, su primera mayoría en la legislatura nacional. (CIDOB, 2016)

Tsai, con una formación educativa muy elitista y centrada en la problemática de su país y su ubicación geográfica, se le exigió mucho desde sus inicios. Mujer ambiciosa, preparada y con visión de su entorno tomo decisiones drásticas pero efectivas.

\section{7.2 ¿Cuál es la estrategia de los taiwaneses?}

De las respuestas al Covid-19 con una eficacia mayormente sólida, ya que les antecede la propagación de un virus que fue la antesala de esta nueva pandemia, en el mundo entero.

La respuesta positiva de Taiwán se ha atribuido a su preparación temprana, experiencia en salud, competencia del gobierno y alerta popular. Según el informe del Consejo de Relaciones Exteriores con sede en Estados Unidos, Taiwán alertó a la Organización Mundial de la Salud (OMS) sobre el potencial del coronavirus para la transmisión de persona a persona el 31 de diciembre, pero no recibió respuesta. Una de las alertas más tempranas fuera de China. En cambio, la OMS respaldó la negación de transmisión de persona a persona por parte de China hasta el 21 de enero. Si bien la OMS pareció minimizar la amenaza global, Taiwán adoptó medidas enérgicas para su detección, prueba, localización de contactos y aplicación de cuarentenas. (ASIALINK,2020)

La presidente de Taiwán, Tsai, ha sido elogiada por su liderazgo decisivo durante la crisis del coronavirus. En enero, a la primera señal de una nueva enfermedad, 
implementó 124 medidas para bloquear la propagación, sin tener que recurrir a los bloqueos que se hicieron comunes en otros lugares. (ASIALINK,2020)

Un informe publicado en el Journal of the American Medical Association (JAMA), indicó que el gobierno de Taiwán implementó las lecciones aprendidas de su experiencia con el brote de SARS de 2003. Los equipos de funcionarios entrenados y experimentados reconocieron rápidamente la crisis y activaron las estructuras de gestión de emergencias para abordar el brote emergente...Mediante el reconocimiento temprano de la crisis, las sesiones informativas diarias para el público y los mensajes de salud simples, el gobierno pudo tranquilizar al público entregando información oportuna, precisa y transparente sobre la epidemia en evolución, destaca el informe. (ASIALINK,2020)

Taiwán es un ejemplo de cómo una sociedad puede responder rápidamente a una crisis y proteger los intereses de sus ciudadanos. Al día 14 de mayo, el Centro de Operaciones del Gobierno Central para Emergencias (CECC, siglas en inglés) reportó un nuevo caso importado de COVID-19, aumentando el número total de casos en Taiwan a 437. A pesar de ello, la nación lleva tres semanas sin registrar casos de infección local por COVID-19. (Khaliq, 2020)

El origen y formación de cada una de las mujeres que gobiernan los países mencionados son diversos y las similitudes inexistentes. Su camino para llegar a representar a sus países fue largo y lleno de retos. En algo, sí coinciden, son las primeras mujeres en llegar a dirigir a su país, merito que no puede minimizarse. En la actualidad, hay algo más que las une e identifica, y esto se refiere a la forma en que han logrado controlar la epidemia de COVID19 en sus respectivos territorios. Casos de éxito que muchos países quisieran replicar para evitar contagios y fallecimientos a causa del virus.

En las figuras que a continuación se presentan se pueden identificar las cifras de estos siete países del 15 de abril al 3 de junio 2020: 


\section{Figura 1.}

Cifras de fallecimientos en los siete países en abril, mayo y junio.

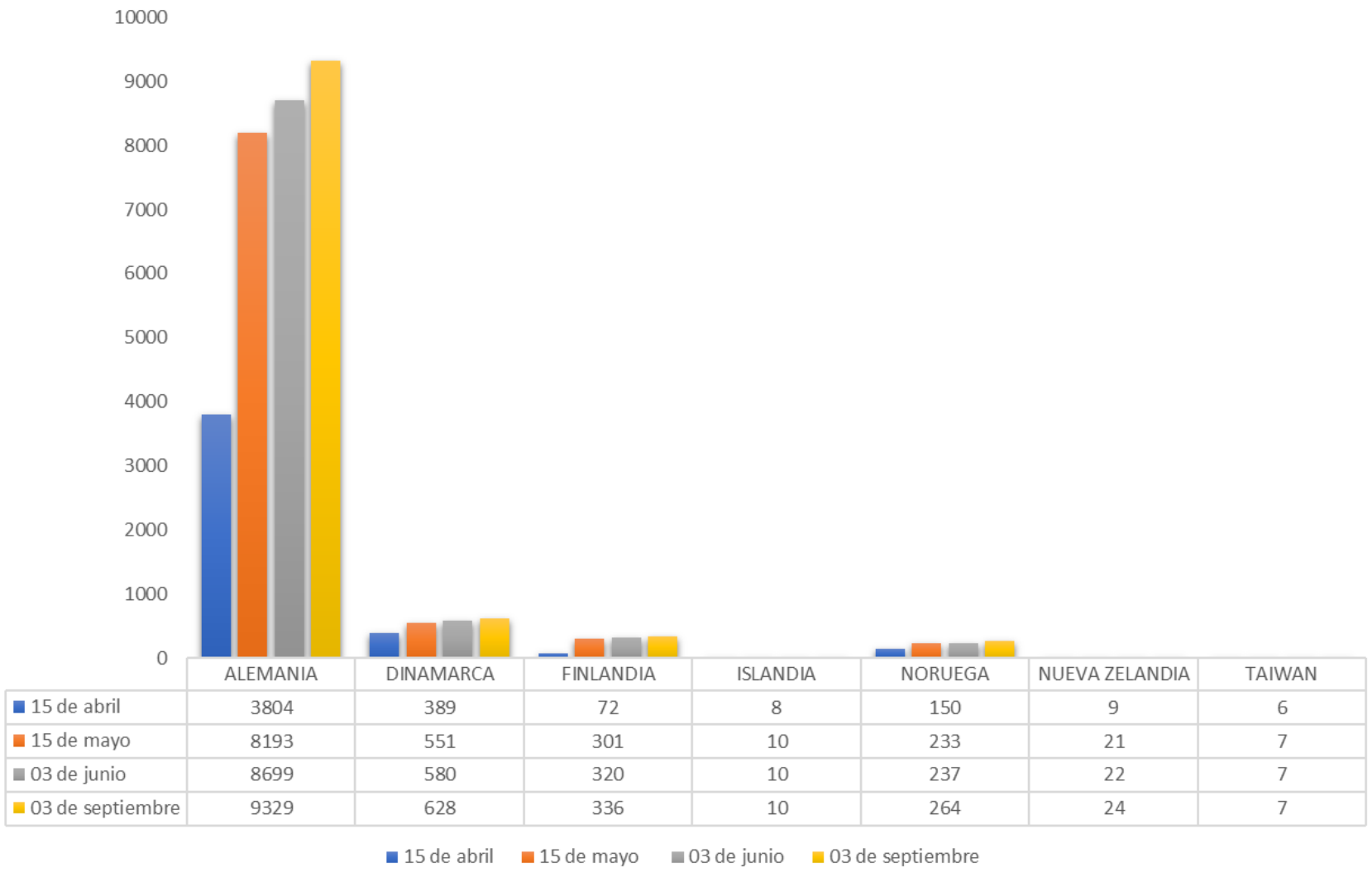

Morales T., López E. \& García J. A.

Las líderes mundiales y sus estrategias ante el COVID-19 
Fuente: Elaboración propia con datos de Organización Mundial de la Salud (OMS,2020).

\section{Tabla 1.}

Validación

\begin{tabular}{|l|r|r|r|r|}
\hline & 15 de abril & 15 de mayo & 03 de junio & $\begin{array}{c}03 \text { de } \\
\text { septiembre }\end{array}$ \\
\hline ALEMANIA & 3804 & 8193 & 8699 & 9329 \\
\hline DINAMARCA & 389 & 551 & 580 & 628 \\
\hline FINLANDIA & 72 & 301 & 320 & 336 \\
\hline ISLANDIA & 8 & 10 & 10 & 10 \\
\hline NORUEGA & 150 & 233 & 237 & 264 \\
\hline NUEVA ZELANDIA & 9 & 21 & 22 & 24 \\
\hline TAIWAN & 6 & 7 & 7 & 7 \\
\hline
\end{tabular}

Fuente: Elaboración propia con datos de Organización Mundial de la Salud (OMS,2020).

Para poder ver gráficamente las cifras reflejadas en fallecimientos de los casos positivos de COVID- 19 en los siete países citados en este artículo, se muestran a continuación la siguiente figura.

\section{Figura 2}

Cifras de fallecimientos en los siete países en abril, mayo y junio 2020 

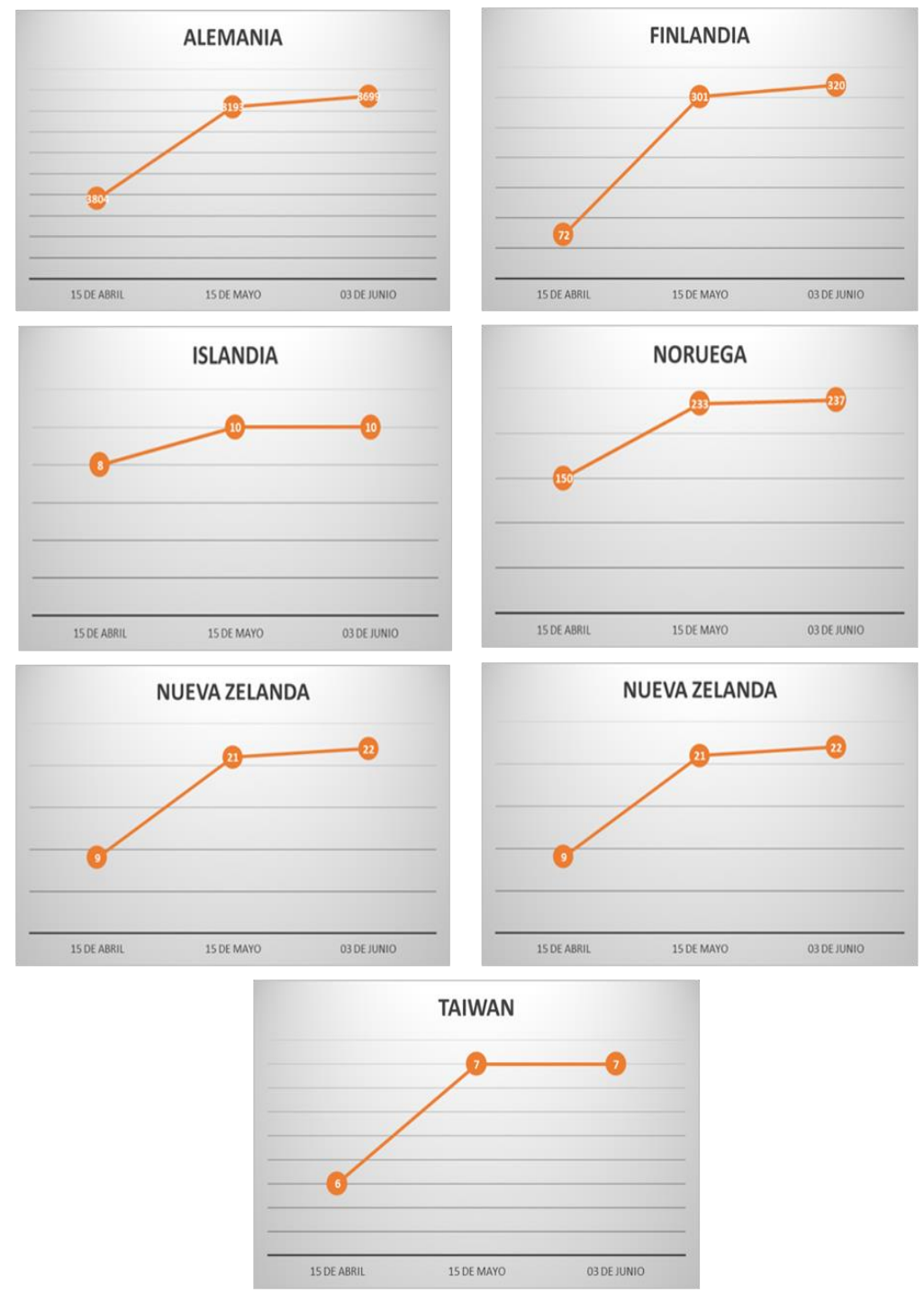

Fuente: Elaboración propia con datos de la Organización Mundial de la Salud (OMS, 2020).

\section{CONCLUSIONES}

Todas ellas dan evidencia de gestiones eficientes, prácticas, claras, directas y firmes. Todas han aumentado su popularidad por su rápida reacción ante la problemática de la pandemia. Son mujeres carismáticas y con una historia de vida muy diferentes, pero 
coinciden en su determinación, el valor de su trabajo, la forma en que priorizan el mismo y sobre todo que permitieron asesorarse con especialistas en la materia, los escucharon e implementaron estrategias que dieron resultados positivos. Quizá por ello son motivo de observación, de análisis sobre sus personalidades y su estilo de gestión pública en cada uno de sus países. Alemania, Dinamarca, Finlandia, Islandia, Noruega, Nueva Zelanda y Taiwán tienen un poder adquisitivo alto, con sistema de salud bien preparado y ciudadanos conscientes, que han acatado las indicaciones por parte de las autoridades. Estos siete ejemplos de mujeres permitan identificar el éxito de sus roles de gestión adecuados ante lo desconocido.

Identificación del problema, asesoramiento por parte de los expertos, no interferencia con los resultados de estudios, claridad en su comunicación, firmeza en sus decisiones, gestión adecuada de recursos, sistemas de salud preparado ya que son países que cuentan con un estado de bienestar para sus ciudadanos, empatía con sus conciudadanos...podrían ser las claves del éxito, solo la historia lo juzgará.

Aún es pronto saber los resultados de todas las estrategias utilizadas por los gobiernos. La propagación del virus no es de fácil control, si bien ha disminuido aparentemente, no se puede predecir cuál será su comportamiento en un futuro cercano. Lo que sí es evidente es que los países liderados por mujeres tomaron medidas que han mantenido en niveles bajos la tasa de contagios y muertes de COVID-19. 


\section{REFERENCIAS}

ABC Internacional (2020, 23 marzo) ¿Por qué en Alemania mueren menos personas por coronavirus? www.abc.es/sociedad/abci-alemania-mueren-menos-personas-coronavirus 202003202116 noticia.html

ASIALINK América. Economía. (2020, Mayo 5) Taiwán completa 3 semanas sin contagios locales de coronavirus. Retrieved July 11, 2020, from AsiaLink América. Economía website: https://asialink.americaeconomia.com/economia-y-negocios-macroeconomiasociedad/taiwan-completa-3-semanas-sin-contagios-locales-de-coronavirus

BBC News Mundo. (2020, June 8). ¿Cómo Nueva Zelanda llegó a dar por eliminado el coronavirus y levantar las restricciones (y qué papel jugó Jacinda Ardern)? BBC News Mundo. Retrieved from https://www.bbc.com/mundo/noticias-internacional-52448237

BIOGRAFÍA DE ANGELA MERKEL. Retrieved July 11, 2020, from Biographia corta website: http://www.biografiascortas.com/2012/01/biografia-de-angela-merkel.html

CIDOB. (2013, November). Retrieved July 11, 2020, from CIDOB website: https://www.cidob.org/biografias lideres politicos/europa/noruega/erna solberg

CIDOB. (2016, January). Retrieved July 11, 2020, from CIDOB website: https://www.cidob.org/biografias lideres politicos/asia/taiwan republica de china/tsai ing wen

CIDOB. (2017a, November). Retrieved July 11, 2020, from CIDOB website: https://www.cidob.org/biografias lideres politicos/oceania/nueva zelanda/jacinda arde $\underline{\mathrm{rn}}$

CIDOB. (2017b, December). Retrieved July 11, 2020, from CIDOB website: https://www.cidob.org/biografias lideres politicos/europa/islandia/katrin jakobsdottir

CIDOB. (2019a, July). Retrieved July 11, 2020, from CIDOB website: https://www.cidob.org/biografias lideres politicos/europa/dinamarca/mette frederiksen

CIDOB. (2019b, December). Retrieved July 11, 2020, from CIDOB website: https://www.cidob.org/biografias lideres politicos/europa/finlandia/sanna marin

Corral, $\mathrm{T}$. (2020, abril 4). La estrategia de Finlandia para hacerle frente a la crisis económica. Retrieved from www.lainformación.com: https://www.lainformacion.com/mundo/finlandia-medidascoronavirus-influencers/6556329/

Cuddy, A. (2009) "Just Because I'm Nice, Don't Assume I'm Dumb." Breakthrough Ideas of 2009. Harvard Business Review 87, no. 2 (February 2009).

DW (2020). Angela Merkel sobre el coronavirus. 18 -03- 2020, de DW Made for minds Sitio web: https://www.dw.com/es/angela-merkel-sobre-el-coronavirus-somos-una-comunidad-enla-que-cada-vida-y-cada-persona-cuentan/a-52830982

Gideion, U., \& Góngora, P. (2020, May 25). La estrategia Alemana frente al COVID-19: acciones multisectoriales. Retrieved July 11, 2020, from Gente Saludable website: https://blogs.iadb.org/salud/es/alemania-covid-19/ 
Johnson, B. (2020, May 18). Estas fueron las claves del éxito de Islandia contra el coronavirus. Retrieved July 11, 2020, from MIT Technology Review website: https://www.technologyreview.es/s/12247/estas-fueron-las-claves-del-exito-de-islandiacontra-el-coronavirus

López, M. (01/04/20). Alemania intriga a los epidemiólogos por sus cifras sobre coronavirus, Barcelona, España, https://www.lavanguardia.com/vida/20200401/48260217880/alemania-intrigaepidemiologos-cifras-coronavirus-covid-19-pandemia-contagios-video-seo-lv.html

Makooi, B. (2020, April 13). Dinamarca: ¿excepción europea ante el Covid-19? Retrieved July 11, 2020, from France 24 website: https://www.france24.com/es/20200413-dinamarcaexcepcion-europa-covid19-coronavirus-cuarentena

Organización mundial de la Salud, (2020). Figura 1. Recuperado de http://Organización Mundial de la Salud (who.int)

Organización mundial de la Salud, (2020). Figura 2. Recuperado de http://Organización Mundial de la Salud (who.int)

Redacción. (2020, mayo 15). La Vanguardia. Retrieved junio 3, 2020, from Finlandia anuncia que ha frenado la pandemia y ya ha superado su pico: https://www.lavanguardia.com/vida/20200515/481151763243/finlandia-anuncia-que-hafrenado-la-pandemia-y-ya-ha-superado-su-pico.html

Revista Proceso. (2020). Nueva Zelanda se declara libre de COVID-19 y regresa a la "normalidad" México https://www.proceso.com.mx/nacional/2020/6/8/nueva-zelanda-se-declara-libre-decovid-19-regresa-la-normalidad-244159.html

Riyaz Khaliq. (2020). La estrategia de contención de Taiwán da frutos y no se reportan casos evos. 15-04-2020, de Anadolu Agency Sitio web: https://www.aa.com.tr/es/mundo/la-estrategiade-contenci\%C3\%B3n-de-taiw\%C3\%A1n-da-frutos-y-no-se-reportan-casosnuevos/1805826

Visitnorway Coronavirus COVID-19 en Noruega: así afecta a los viajes. (2020, July 1). Recuperado July 11, 2020, from www.visitnorway.es website: https://www.visitnorway.es/organiza-tuviaje/informacion-coronavirus-covid-19/ 